\title{
Effectiveness of CBI in Improving Agricultural Major Students' English Proficiency and Learning Motivation
}

\author{
Liya Liu \\ Huazhong Agricultural University, Hubei 430070, China. \\ liuliya@mail.hzau.edu.cn,624652539@qq.com
}

Keywords: Theme-based content-based instruction; English proficiency; learning motivation.

\begin{abstract}
This paper reviews an English teaching practice based on CBI in an agricultural university in China. 135 students majoring in agricultural science participated in the experimental teaching project. Tests, questionnaires and semi-structural interviews were conducted to evaluate the effects of the teaching practice on students' language skills and their feedback. The statistical results indicate that this teaching practice proves to be more effective in improving language skills of students of higher English proficiency and triggering their motivation in language learning. The purpose of the study is to provide empirical evidence for the feasibility and effects of CBI in college English teaching in agricultural university.
\end{abstract}

\section{Introduction}

Since 2011, bilingual education has been carried out in higher education in China. As one of the national key universities, it has been practiced simultaneously in senior college students for many years. However, a package of problems including communicative failure in English in major courses, increased anxiety and declined motivation in bilingual classes move us to reflect on college English teaching which is supposed to prop up the senior bilingual education. In order to develop students' motivation and communicative skills in academic English, the present study reformed the traditional college English teaching with a framework of content based instruction. Hopefully the model based on CBI can contribute to bridging the gap between college English and senior bilingual education in our university.

\section{Literature Review}

\subsection{CBI and the Theoretical Support.}

CBI (Content-based Instruction) originated from the immersion class in Canada in the 1960s [1]. The teaching model of CBI combines the language study with the subject study in which students can improve their language skills through the study of subject matter. It aims to construct a learning environment where language is a real tool for communication. The three most popular models of CBI are theme-based model, sheltered model and adjunct model. In a course of theme-based instruction the contents of the course are organized around themes that form the basis for language analysis. A sheltered model, students are taught content courses in the second language by a content-area teacher with some emphasis on developing their language skills. In an adjunct model, students concurrently take a content course and a related language course and have to fulfill the requirements of both courses.

The theoretical support of CBI teaching model comes from the Input Hypothesis by Stephen D. Krashen and the Learning Motivation Theory by Gardner. According to Krashen [2], the learning of language is a conscious process, while the acquisition of language is a subconscious process. In English class based on CBI, the students acquire the language through the learning of subject matter. English is used as a tool to code and decode meaning in comprehending and communicating the subject matter. This is a process where English acquisition occurs subconsciously and the learners may lose the pressure coming from the traditional English class by concentrating on their subject learning. 


\subsection{Pedagogical Research on CBI.}

In recent years CBI has received increasing attention and support in education. Linguistic benefits resulted from CBI model have been achieved by a bunch of research and programs [2-3]. It has been applauded as a valuable curricular approach in a wide range of educational contexts [4-6].

In the 1980s, CBI entered into the kingdom of Chinese foreign language study. Many educators have made empirical study and further discussion on CBI [7-10]. In addition, various models of CBI has been explored to fit into different teaching scenario in the field of ESP. A sheltered model of CBI has been adopted to improve the Chinese of foreign students in Nanjing University. A theme-based CBI has been carried out in Huazhong agricultural university ${ }^{[11]}$. Their studies on CBI all share some findings in common. Firstly, CBI increase students' academic achievement. Secondly, CBI is more effective in arousing students' interests in learning a foreign language. However, what specific model of CBI can be best adaptive to students majoring in agricultural science is still worth exploring. Therefore, the present study attempt to test the effects of the theme-based CBI on students' English skills and their motivation in English learning.

\section{Empirical Study}

\subsection{Purpose.}

The paper attempts to explore the following questions. Firstly, is it more effective to enhance English learning in the theme-based CBI model. Secondly, how does students' language skills and motivation get changed in this model.

\subsection{Subjects.}

The subjects were 135 first year non-English majors from Huazhong Agriculture University. According to the test performance in band 2 final examination, students of the same level were divided into experimental group and control group as shown in table 1 . The statistics indicated that there was no significant difference in linguistic performance between the two groups $(p=.896>.01)$.

Table 1 Pretest Scores of the Subjects

\begin{tabular}{|c|c|c|c|c|c|}
\hline Group & Number & Average Mark & Std. Deviation & $\mathrm{T}$ & $\mathrm{P}$ \\
\hline Experimental group & 135 & 73.8370 & 6.10475 & \multirow{2}{*}{.130} & \multirow{2}{*}{.896} \\
\hline Control group & 135 & 73.7370 & 6.49478 & \multirow{2}{*}{.040} \\
\hline
\end{tabular}

\subsection{Instruments.}

The instrument includes a band 2 test, a band 4 test from CET 4 and a semi-structured interview. The interview includes a questionnaire in which there are altogether 15 questions focusing on students' evaluation of college English learning on a five-point Liker Scale (1=strongly disagree, $2=$ disagree, $3=$ neutral, $4=$ agree, $5=$ strongly agree).

\subsection{Procedure.}

The experiment initiated at the beginning of the second term. Both groups shared the same textbooks and class hours. What distinguishes experimental group from control one was the theme-based CBI teaching model. In this model teaching materials were adapted and reorganized around themes related to their major study. After one year experiment, their linguistic performance was recorded and compared to reveal any distinction resulted from the different learning models.

\section{Results and Discussion}

As reflected in table 2, a comparison between pretest and posttest performance of experimental group reveals a marked advance with statistical significance. It indicates that the theme-based CBI teaching model is effective to enhance students' English skills. However, the average marks on overall performance of the different groups are very close as indicated in table 3 though the average marks of experimental groups show more improvement from pretest to posttest. This reflects that in the present experiment the theme-based CBI model doesn't show statistical superiority to other teaching models in improving students' English skills for general purposes. 
Table 2 Pretest and Post-test Scores of the Experimental Group

\begin{tabular}{|c|c|c|c|c|c|}
\hline Test & Number & Average Mark & Std. Deviation & $\mathrm{T}$ & $\mathrm{P}$ \\
\hline Pretest & 135 & 73.8370 & 6.10475 & \multirow{2}{*}{6.714} & \multirow{2}{*}{.000} \\
\hline Post-test & 135 & 79.5963 & 5.91024 & & \\
\hline
\end{tabular}

Table 3 Post-test Scores of the Subjects

\begin{tabular}{|c|c|c|c|c|c|}
\hline Group & Number & Average Mark & Std. Deviation & $\mathrm{T}$ & $\mathrm{P}$ \\
\hline Experimental group & 135 & 79.5963 & 5.91024 & \multirow{2}{*}{-1.188} & \multirow{2}{*}{.236} \\
\hline Control group & 135 & 78.7333 & 6.02631 & & \\
\hline
\end{tabular}

To zoom in for more details on how the theme-based CBI teaching model exert influence on students' performance in post-test, the author selected the top 40 students from the two groups respectively. The data from table 4 shows that students of higher English proficiency from the experimental group demonstrate significant difference of improvement in test performance from those of the control group. This is a statistical evidence to prove that the theme-based CBI is more effective in motivating students of higher proficiency.

Table 4 Post-test Scores of the Subjects of Higher English Proficiency

\begin{tabular}{|c|c|c|c|c|c|}
\hline Group & Number & Average Mark & Std. Deviation & $\mathrm{T}$ & $\mathrm{P}$ \\
\hline Experimental group & 40 & 82.8500 & 2.89606 & \multirow{2}{*}{2.979} & \multirow{2}{*}{.004} \\
\hline Control group & 40 & 80.0000 & 2.65301 & & \\
\hline
\end{tabular}

Table 5 Students' Feedback of the Theme-based CBI Model

\begin{tabular}{|c|c|c|}
\hline & Experimental group & Control group \\
\hline $\begin{array}{l}\text { It is beneficial to future research work to take English } \\
\text { class. }\end{array}$ & $\begin{array}{cc}1 .-0 \% & 2 .-0 \% \\
3 .-2 \% & 4 .-12 \% \\
5 .-86 \%\end{array}$ & $\begin{array}{c}1 .-0 \% \quad 2 .-5 \% \\
3 .-63 \% \\
4 .-18 \% \\
5 .-14 \%\end{array}$ \\
\hline $\begin{array}{l}\text { Involved in activities and tasks I feel English as a vehicle } \\
\text { for communication rather than grammatical rules. }\end{array}$ & $\begin{array}{cc}1 .-0 \% & 2 .-3 \% \\
3 .-3 \% & 4 .-6 \% \\
5 .-88 \%\end{array}$ & $\begin{array}{c}1 .-0 \% \quad 2 .-16 \% \\
3 .-30 \% \\
4 .-26 \% \\
5 .-28 \%\end{array}$ \\
\hline English classes awaken my initiative in learning English. & $\begin{array}{cc}1 .-0 \% & 2 .-2 \% \\
3 .-13 \% & 4 .-5 \% \\
5 .-80 \%\end{array}$ & $\begin{array}{c}1 .-0 \% \quad 2 .-22 \% \\
3 .-60 \% \\
4 .-13 \% \quad 5 .-5 \%\end{array}$ \\
\hline
\end{tabular}

A first-hand evaluation of the adopted teaching model was conducted afterwards. The data (table5) reflects that students approves of and have benefited from the new learning model. Almost 98\% students in experimental group approve the necessity of the theme-based CBI in English learning class as a basis for future research work and expect for more academic achievements in future study. In contrast to 18\% of control group students, $85 \%$ students hold that English classes awaken their initiative in learning English. According to the semi-structured interviews, most of those students attribute it to the theme-based CBI English classes their very desirable academic performance of future research work.

\section{Conclusion}

In this theme-based CBI teaching model, the teacher coordinated four factors to contribute to the effectiveness of English teaching. Firstly, the teaching resource are published research papers and speeches on related topics to guarantee the authenticity of learning materials. Secondly, the grammar items are carefully and systemically selected to be covered in the content-based curriculum to achieve a balance between language and content. Thirdly, the teacher plays a role of facilitator to motivate learners and the learners are initiative in learning projects and activities. Fourthly, English is a vehicle for communication. It is used to convey meaning in cooperation with partners and presentation of students' own ideas. 
In consistent with the finding in the research of Yuan, Cai, Cao \& $\mathrm{Li}^{[8,11,12]}$, the present study verifies the efficiency of the theme-based CBI teaching model in promoting English skills of students especially those of higher proficiency. What's more, students' motivation especially their initiative in leaning language are promoted. In addition to the above, the favorable evaluation from the students proves the practical feasibility and validity of the theme-based CBI teaching model in the agricultural university.

\section{Acknowledgement}

This research was financially backed by Project 2662015RW005 supported by the Fundamental Research Funds for the Central Universities.

\section{References}

[1] Johnson, R.K. \& Swain, M. Immersion Education: International Perspectives, Cambridge University Press, Cambridge, 1997

[2] Krashen, S. The Input Hypothesis: Issues and Implications, Longman, London, 1985

[3] Genesee, F. Learning through Two Languages: Studies of Immersion and Bilingual Education, Newbury House, Cambridge, 1987

[4] Mohan, B. Language and Content, Addison-Wesley Company, Massachusetts, 1986

[5] Snow, M. \& Brinton, D. Content-Based Language Instruction: Investigating the Effectiveness of the Adjunct Model. TESOL Quarterly, 22/4 (1988) 553-574

[6] Snow, M., Met, M. \& Genesee, F. A Conceptual Framework for the Integration of Language and Content in Second/Foreign Language Instruction. TESOL Quarterly, 23/2 (1989) 201-218

[7] Jun-Yue CHANG \& Hai-Nan DONG. An Empirical on the Problems of Implementing CBI among the First-year English Majors. Foreign Languages and Their Teaching, 5 (2008) 37-40

[8] Ping-Hua YUAN, Ting Liu, Li-Juan Wang, CBI the Impact of CBI on EFL Learners' Use of English Strategies and Their English Proficiency, Contemporary Foreign Languages Studies, 9 (2010) 55-60

[9] Li-Ming Yu \& Jian-Xia HAN. CBI in Ottawa and its Inspiration. Foreign Language Teaching and Research, 35 (2003) pp465-468

[10] Feng-Long CAO \& Ke LI. Effects of Content-based Instruction on Medical Students' Motivation of English Learning and Language Skills. Computer-Assisted Foreign Language Education, 162 (2015)

[11] Yan-Ling GUO. On Effectiveness of CBI in Improving Maritime Major Students' English Proficiency and Learning Motivation-A Research Based on The Survey in Dalian Ocean University. Shanghai Foreign Languages University Doctor's Thesis, 2012

[12] Pei-Sheng CAO. An Emperimental Study on the Effectiveness of CBI Theme-based Teaching Mode in College English Teaching. Computer-Assisted Foreign Language Education, 145 (2012) 